\title{
A Self-sustainable Solar Desalination System Using Direct Spray Technology
}

\author{
Chen Qian ${ }^{1, *}$, Raid Alrowais ${ }^{1}$, Muhammad Burhan ${ }^{1}$, Doskhan Ybyraiymkul ${ }^{1}$, Muhammad Wakil Shahzad ${ }^{1,2}$, \\ Li Yong ${ }^{3}$, Kim Choon $\mathrm{Ng}^{1, *}$ \\ 1. Water Desalination and Reuse Center, King Abdullah University of Science and Technology, Thuw \\ al 23955, Saudi Arabia \\ 2. Northumbria University, Newcastle upon Tyne, United Kingdom \\ 3. Institute of Refrigeration and Cryogenics, Shanghai Jiao Tong University, Shanghai, 200240, Chin \\ $a$ \\ *Corresponding Authors, email: chen_qian@u.nus.edu; kimchoon.ng@kaust.edu.sa
}

\begin{abstract}
Solar desalination offers a sustainable solution to growing global water demand due to the geographical coincidence between high solar availability and severe water scarcity. This paper presents a self-sustainable solar desalination system using a direct-contact spray technology, i.e. the spray-assisted low-temperature desalination technology. This technology employs a tubeless design for both evaporators and condensers, which not only enhances heat and mass transfer but also reduces the initial plant cost. In this study, solar thermal collectors are employed to completely satisfy the energy requirements of the proposed desalination system, and heat storage tanks are used for seasonal thermal storage and management. A mathematical model is firstly developed and validated with laboratory pilot for the proposed large-scale solar-powered desalination system. Afterward, the long-term productivity and energy efficiency of the system is evaluated under the climatic conditions of Makkah, Saudi Arabia. The proposed solar desalination system is able to provide an uninterrupted water supply of $20 \mathrm{~kg} /$ day for per square meter solar collector area, which is much higher than other thermal desalination processes. The freshwater production rate is found to be determined by the interaction of the three subsystems, i.e. efficiency of the solar collectors, temperature and heat losses in the storage tank, and energy efficiency of the desalination system. With a collector area of $360 \mathrm{~m}^{2}$, the annual productivity is maximized when the feed flowrate is $1.7 \mathrm{~kg} / \mathrm{s}$ and the diameter of the heat storage tank is $1.9 \mathrm{~m}$. The desalination cost is estimated to be $\$ 1.29 / \mathrm{m}^{3}$, which is much lower than other thermal desalination systems driven by solar energy.
\end{abstract}

Keywords: self-sustainable; solar desalination; direct spray; long-term performance;

\section{Introduction}

Global desalination capacity has been growing exponentially in the past decades due to the growth of the world population and the development of advanced desalination technologies [1]. In the Gulf Cooperation Council (GCC) countries, desalination has become a major source of potable water supply. For countries like Kuwait and Qatar, 100\% of industrial and domestic water supplies come from desalination [2].

Desalination processes are energy-intensive by nature, and the energy demands are usually met by burning a substantial amount of fossil fuels [2]. Such a high fuel consumption not only leads to severe environmental impacts (e.g. air pollution and greenhouse gas emission) but also limits desalination plants to energyaffluent areas [3, 4]. Therefore, it is essential to search for alternative energy sources that are widely available and environmental-friendly, such as solar energy, geothermal energy, and industrial waste heat. 
Solar energy is deemed to be the most promising alternative to fossil fuels due to the geographical coincidence between high solar availability and severe water scarcity. Most of the existing desalination processes can be coupled with solar energy, and extensive research efforts have been reported on this subject. Mamouri et al [5] designed a solar still using thermosiphon heat pipes and vacuum glasses. The production was reported to be $1.02 \mathrm{LPH} / \mathrm{m}^{2}$ and the maximum efficiency was $22.9 \%$. Kasaeian et al [6] conducted a thorough review of solar-driven humidification dehumidification (HDH) systems. Different types of solar collectors have been employed to drive the HDH cycle, including flat plate, bubble column, evacuated tube, concentrating, and PV collectors. Manolakos [7] reported two solar-RO desalination systems, namely, PV-RO and RO-solar Rankine system. The PV-RO system has a specific energy consumption of $3.8-6 \mathrm{kWh} / \mathrm{m}^{3}$, while the value for the RO-solar Rankine system is reduced to $2-3 \mathrm{kWh} / \mathrm{m}^{3}$. Lee et al [8] simulated a multi-stage direct contact membrane distillation system powered by solar energy. Under the climatic condition of Busan, Korea, the monthly average daily production rate was reported to be $0.4 \mathrm{~m}^{3} /$ day, while the thermal efficiency was $45 \%$. Al-Othman et al [9] simulated a multi-stage flash (MSF) desalination plant driven by parabolic trough collectors (PTC) and a solar pond. The designed plant had a production rate of $1880 \mathrm{~m}^{3} /$ day, and the required energy was provided by two PTCs with a total area of $3160 \mathrm{~m}^{2}$ and a $0.53 \mathrm{~km}^{2}$ solar pond. Raphael et al [10] conducted a transient simulation on a solar-driven multi-effect desalination with a thermal vapor compressor (MED-TVC) system. The required volume of the accumulator was calculated to be $12 \mathrm{~m}^{3}$ to meet $30 \mathrm{~min}$ steam demand during cloud cover.

Most of the aforementioned solar desalination processes are facing key limitations and challenges. For example, solar stills, solar-HDH, and solar-RO are usually limited to small-scale operation. Large-scale thermal processes like MED and MSF driven by solar energy are technically viable, but both systems have high initial capital costs due to the requirement of a large heat transfer area. In this regard, it is critical to developing new desalination processes with low costs, simple operation, and easy maintenance.

The spray-assisted low-temperature desalination technology (SLTD) is an emerging process that potentially mitigates the issues faced by existing desalination systems [11]. It employs a tubeless design for both evaporators and condensers, while heat input occurs external to the water boxes by using cost-effective heat exchangers. The hot seawater partially flashes into vapor in the low-temperature evaporators, and the produced vapor is condensed in the neighboring condensers by the injection of cooling water. Since there is no tube inside the evaporators and condensers, these components are cost-effective, leading to a significant reduction in initial plant cost $[12,13]$. The simplicity of the component design also enables easy operation and maintenance, thus reducing the operational requirements and costs [14].

Extensive studies have been reported on the SLTD system. Mutair and Ikegami $[15,16]$ measured the evaporation rate of water in a spray evaporator. A dramatic temperature drop of the seawater was observed, indicating dramatic flash evaporation. Yasuyuki et al. [17] compared the evaporation rates when water was sprayed from different directions, and the upward spray was observed to have the highest evaporation rate. El-Agouz et al [18] tested a spray desalination system integrated with a $1-\mathrm{m}^{2}$ solar thermal collector. The daily freshwater yield was measured to be $9 \mathrm{~L}$, much higher than that of an HDH system operated under similar climatic conditions. Chen et al. [19] numerically evaluated the solar-powered spray desalination system in Singapore, and the annual average production rate was predicted to be $4 \mathrm{~L} / \mathrm{day}-\mathrm{m}^{2}$. Maidment [20] conducted a similar study by considering the available waste heat in Cyprus, and the spray desalination system was able to produce 11.25 million $\mathrm{m}^{3}$ of freshwater every year. Chen et al. [21, 22] conducted a thermodynamic analysis on the multi-stage SLTD system, which recovered the condensation heat for seawater heating. The energetic and exergetic efficiencies for the multi-stage configuration were found to be greatly improved compared with the single-effect system. Wellmann et al [14, 23] reported a multi-stage SLTD system driven by the waste heat of a CSP (concentrated solar power) plant. The desalination cost 
was calculated to be $0.4-0.85 \mathrm{USD} / \mathrm{m}^{3}$, depending on the electricity cost. Chen et al. [12] integrated the SLTD system with thermal vapor compression (TVC). The energy consumption for desalination was reduced by $10-30 \%$ after TVC integration, while the initial plant cost almost remained unchanged.

Most of the above-mentioned studies on solar-driven SLTD employed a single-effect configuration, which has low productivity and thermal efficiency. Large-scale SLTD systems with multi-stage configurations have also been covered, but they investigated only the SLTD system itself without solar coupling. Comparing with a normal SLTD system, a solar-driven desalination system requires unique design and operational strategies, e.g. thermal storage and management. Meanwhile, the SLTD system performance also impacts the efficiency of solar thermal collectors. Therefore, the optimal performance will be determined by the interactions of different subsystems. However, to the best of our knowledge, evaluation and optimization of the solar-driven SLTD system have not been reported.

In this work, a solar-driven SLTD system with thermal energy storage and temperature modulation has been evaluated. A mathematical model has been developed and validated using experimental data from a lab pilot plant. Employing the model, the long-term performance of the solar-driven SLTD system has been evaluated using the meteorological data of Makkah, Saudi Arabia. A parametric study has also been conducted to optimize the design and operational parameters. Employing the optimal design, the cost of freshwater has been calculated and compared with other existing technologies.

\section{System description}

Figure 1 shows the schematic of a self-sustainable solar desalination system using direct spray technology. The system consists of three subsystems, namely, (1) solar thermal collectors, (2) heat storage tanks, and (3) a spray-assisted low-temperature desalination system (SLTD). The storage tanks are connected in topto-bottom arrangement to achieve thermal stratification. Hot water is withdrawn from the top of Tank 1 for seawater heating in HEX2. After that, a portion of the hot water is mixed with water from the bottom of Tank $\mathrm{N}$ and then circulated through the solar thermal collectors, while the rest is mixed with hot water from Tank 1 to control the heating temperature. The flowrates of these streams are controlled by valves VH1 and VH2. The water leaving the solar collectors is injected into the tank with a temperature that is closest but lower than the solar collector outlet temperature (controlled by valves V1-VN). This filling scheme ensures that Tank 1 has the highest temperature, which will boost the performance of the SLTD system. More details of the flow control scheme can be found in our previous publications [24, 25].

The SLTD system is made up of several spray evaporator-condenser stages and two sets of heat exchangers. Both the spray evaporators and condensers are empty chambers without any metallic surface for heat transfer. Hot seawater percolates into the evaporator that is at a low-pressure condition and flash evaporation emerges. The produced vapor is condensed in the neighboring condenser by the injection of cooling water. By repeating this process in successive evaporator-condenser stages, cooling water will leave the system from the first stage carried with it the condensation heat. The condensation heat is recovered to pre-heat the intake seawater in $H E X 1$, after which the seawater is further heated by the hot water from the heat storage tank. More information about process flow in the SLTD system is available in our previous publications [21, 22], and the readers are referred to these papers for more details. 


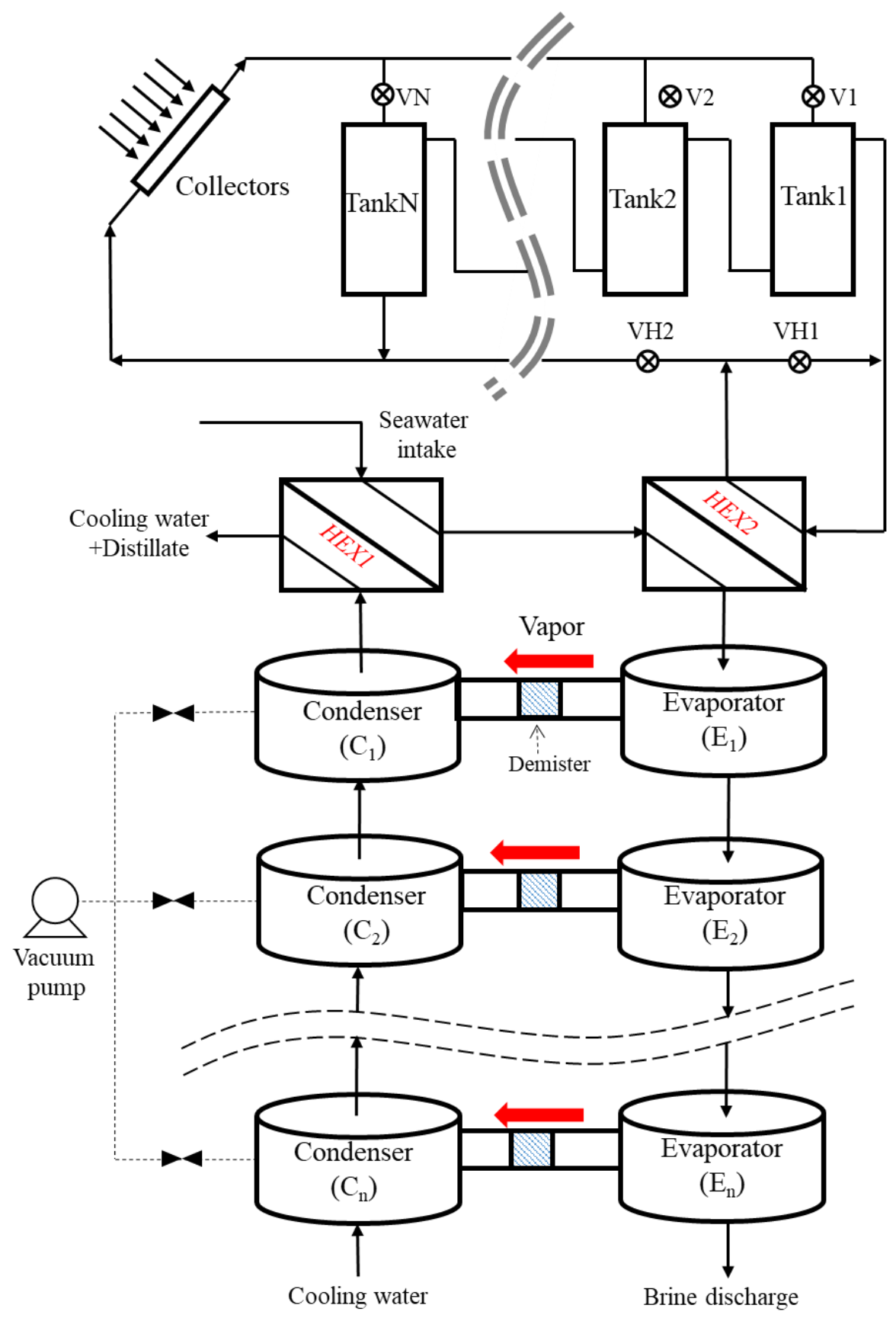

Figure 1 Schematic of the solar-powered spray-assisted low-temperature desalination system coupled with thermal energy storage

\section{Mathematical modelling}

The mathematical models for the proposed solar desalination system consist of the solar thermal collectors, the thermal storage tanks, and the SLTD system. Four heat storage tanks are employed in this system, which will provide sufficient temperature regulation capability with a moderate cost [24, 25]. Figure 2 provides 
the schematic diagrams of the system components with a list of the symbols used in the mathematical model.

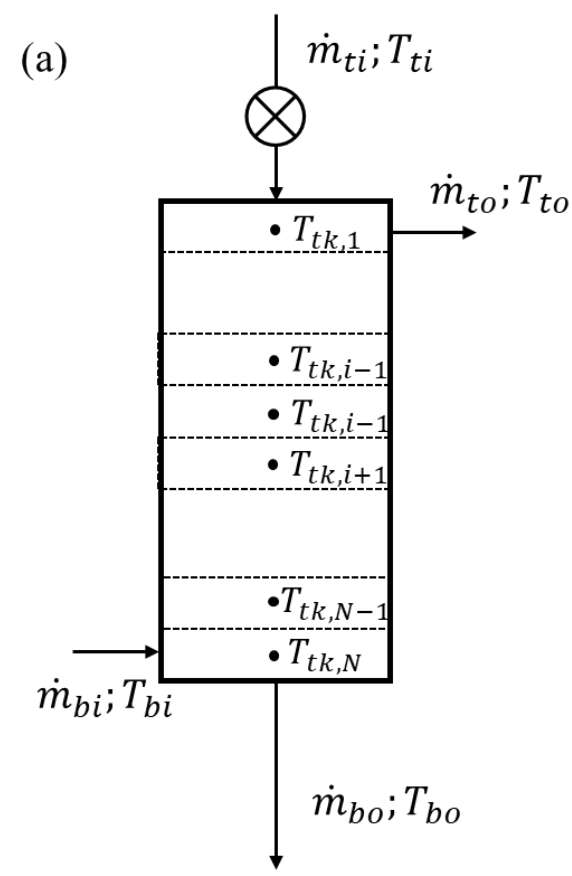

(b)

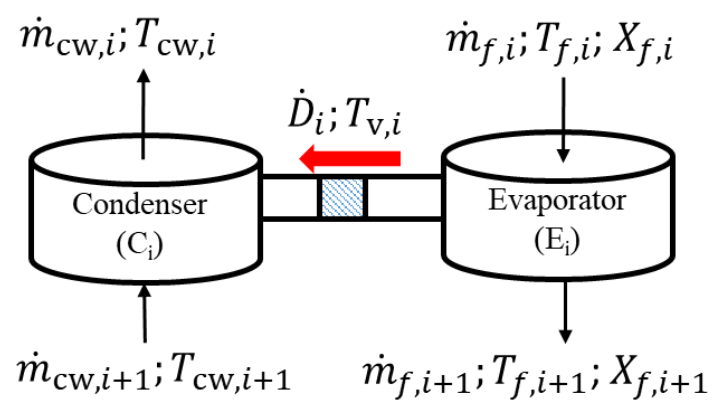

(c)

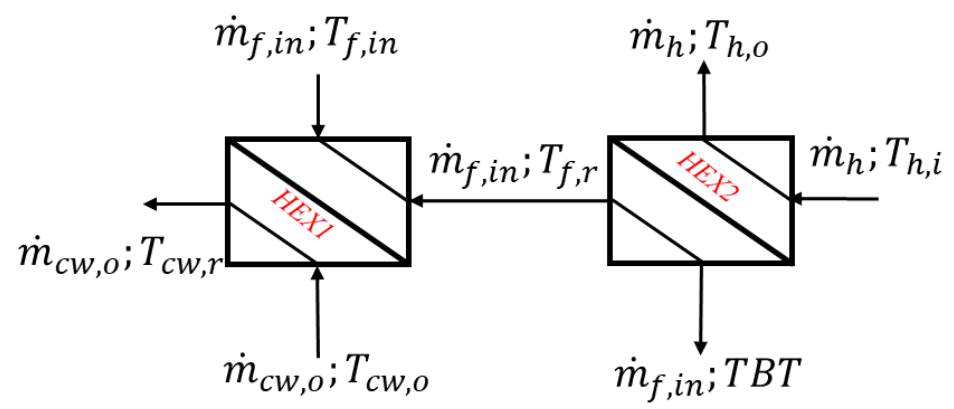

Figure 2 Schematic of the system components: (a) heat storage tank, (b) working stages of the desalination system, and (c) heat exchangers and solar collector

The thermal storage tanks are simulated using the multi-node model. As shown in Figure 2(a), each thermal storage tank is divided into several disk-shaped control volumes. The energy balance equation for each control volume is established by considering convective heat transfer, diffusive heat fluxes, and heat losses to the ambient. The following assumptions are made for the heat storage tank:

(1) The storage tank is made up of $\mathrm{N}$ disk-shaped control volumes, and each control volume is considered to have a uniform temperature;

(2) The incoming flow in each control volume is fully mixed with the rest of fluid in the control volume;

(3) The flow is incompressible, and the overall fluid mass in each control volume remains unchanged.

Table 1 is a summary of the equations describing the tank performance, where $\dot{m}_{t i}$ and $\dot{m}_{t o}$ denote in-flow and out-flow on the top of the tank, respectively, while $\dot{m}_{b i}$ and $\dot{m}_{b o}$ represent in-flow and out-flow at the bottom, respectively. Table 2 summarizes the values of these flowrates under different flow schemes.

Table 1 Mathematical model for the heat storage tanks

\begin{tabular}{|c|c|c|}
\hline Equation & Number & Comments \\
\hline $\begin{aligned} \Delta m_{i} c_{p} \frac{d T_{t k, i}}{d t}= & k A_{i} \frac{T_{t k, i-1}-T_{t k, i}}{\Delta H}+k A_{i} \frac{T_{t k, i+1}-T_{t k, i}}{\Delta H} \\
& -U_{l o s s} A_{H}\left(T_{t k, i}-T_{a m b}\right) \\
& +\left\{\begin{array}{l}\dot{m}_{t k} c_{p}\left(T_{t k, i-1}-T_{t k, i}\right), \text { if } \dot{m}_{t k}>0 \\
\dot{m}_{t k} c_{p}\left(T_{t k, i}-T_{t k, i+1}\right), \text { if } \dot{m}_{t k}<0\end{array}\right.\end{aligned}$ & (1) & $\begin{array}{l}\text { Temperature change in the } \\
\text { heat storage tank for } i^{\text {th }} \text { node, } \\
i=2: N-1 \text {, and } N \text { is the number } \\
\text { of nodes; }\end{array}$ \\
\hline
\end{tabular}




$$
\begin{aligned}
& \Delta m_{1} c_{p} \frac{d T_{t k, 1}}{d t}= k A_{i} \frac{T_{t k, 2}-T_{t k, 1}}{\Delta H}+\dot{m}_{t i} c_{p} T_{t i}-c_{p} T_{t k, 1} \\
&-U_{l o s s} A_{H}\left(T_{t k, i}-T_{a m b}\right) \\
&-\left\{\begin{array}{l}
\dot{m}_{t k} c_{p} T_{t k, 1}, \text { if } \dot{m}_{t k}>0 \\
\dot{m}_{t k} c_{p} T_{t k, 2}, \text { if } \dot{m}_{t k}<0
\end{array}\right. \\
& \Delta m_{N} c_{p} \frac{d T_{t k, N}}{d t}= k A_{i} \frac{T_{t k, N-1}-T_{t k, N}}{\Delta H}+k A_{i} \frac{T_{t k, i+1}-T_{t k, i}}{\Delta H} \\
&+\dot{m}_{b i} c_{p} T_{b i}-\dot{m}_{b o} c_{p} T_{t k, N} \\
&-U_{l o s s} A_{H}\left(T_{t k, i}-T_{a m b}\right) \\
&+\left\{\begin{array}{l}
\dot{m}_{t k} c_{p} T_{t k, N-1}, \text { if } \dot{m}_{t k}>0 \\
\dot{m}_{t k} c_{p} T_{t k, N}, \text { if } \dot{m}_{t k}<0
\end{array}\right. \\
& \dot{m}_{t k}=\dot{m}_{t i}-\dot{m}_{t o}
\end{aligned}
$$

Temperature change in the heat storage tank for $1^{\text {st }}$ node, which is located at the top;

Temperature change in the heat storage tank for $\mathrm{N}^{\text {th }}$ node, which is located at the bottom;

Prevailing flow inside the storage tank; positive value represents downward flow.

\section{Table 2 Inlet and outlet flowrates for each tank under different schemes}

\begin{tabular}{cccccc}
\hline Scheme & Tank & $\dot{\boldsymbol{m}}_{\boldsymbol{t i}}$ & $\dot{\boldsymbol{m}}_{\boldsymbol{t o}}$ & $\dot{\boldsymbol{m}}_{\boldsymbol{b i}}$ & $\dot{\boldsymbol{m}}_{\boldsymbol{b o}}$ \\
\hline$T_{s, o}>T_{t k 1,1}$ & 1 & $\dot{m}_{s}$ & $\dot{m}_{h, t k}$ & 0 & $\dot{m}_{s}-\dot{m}_{h, t k}$ \\
& 2 & $\dot{m}_{s}-\dot{m}_{h, t k}$ & 0 & 0 & $\dot{m}_{s}-\dot{m}_{h, t k}$ \\
& 3 & $\dot{m}_{s}-\dot{m}_{h, t k}$ & 0 & 0 & $\dot{m}_{s}-\dot{m}_{h, t k}$ \\
& 4 & $\dot{m}_{s}-\dot{m}_{h, t k}$ & 0 & 0 & $\dot{m}_{s}-\dot{m}_{h, t k}$ \\
\hline$T_{t k 2,1}<T_{s, o}$ & 1 & 0 & $\dot{m}_{h, t k}$ & $\dot{m}_{h, t k}$ & 0 \\
$<T_{t k 1,1}$ & 2 & $\dot{m}_{s}$ & $\dot{m}_{h, t k}$ & 0 & $\dot{m}_{s}-\dot{m}_{h, t k}$ \\
& 3 & $\dot{m}_{s}-\dot{m}_{h, t k}$ & 0 & 0 & $\dot{m}_{s}-\dot{m}_{h, t k}$ \\
& 4 & $\dot{m}_{s}-\dot{m}_{h, t k}$ & 0 & 0 & $\dot{m}_{s}-\dot{m}_{h, t k}$ \\
\hline$T_{t k 3,1}<T_{s, o}$ & 1 & 0 & $\dot{m}_{h, t k}$ & $\dot{m}_{h, t k}$ & 0 \\
$<T_{t k 2,1}$ & 2 & 0 & $\dot{m}_{h, t k}$ & $\dot{m}_{h, t k}$ & 0 \\
& 3 & $\dot{m}_{s}$ & $\dot{m}_{h, t k}$ & 0 & $\dot{m}_{s}-\dot{m}_{h, t k}$ \\
& 4 & $\dot{m}_{s}-\dot{m}_{h, t k}$ & 0 & 0 & $\dot{m}_{s}-\dot{m}_{h, t k}$ \\
\hline$T_{s, o}<T_{t k 4,1}$ & 1 & 0 & $\dot{m}_{h, t k}$ & $\dot{m}_{h, t k}$ & 0 \\
& 2 & 0 & $\dot{m}_{h, t k}$ & $\dot{m}_{h, t k}$ & 0 \\
& 3 & 0 & $\dot{m}_{h, t k}$ & $\dot{m}_{h, t k}$ & 0 \\
& 4 & $\dot{m}_{s}$ & $\dot{m}_{h, t k}$ & 0 & $\dot{m}_{s}-\dot{m}_{h, t k}$ \\
\hline
\end{tabular}

Figure 2(b) shows the schematic of an evaporator-condenser stage. The process is modelled by analyzing the heat and mass transfer between water and vapor as well as heat and mass balances among different stages. The following assumptions and simplifications are made for the desalination system:

(1) Water and vapor properties are constant in each stage. Water properties are determined by the mean temperature and salinity in the corresponding stage using correlations developed by Sharqawy and Lienhard [26], while vapor properties are determined by the vapor pressure and temperature and are obtained from correlations developed by Wagner and Kruse [27]; 
(2) The produced vapor is salt-free, and there is no entrainment of seawater droplets. Therefore, all the salt remains in the evaporator side;

(3) The evaporators and condensers are high enough to provide sufficient residence time for evaporation and condensation processes to complete;

Table 3 summarizes the model equations for the desalination process. Under a high completion level of evaporation/condensation processes, the values of non-dimensional temperature difference, i.e., $\theta$, are very close to zero $[28,29]$. In this study, a conservative value of $\theta=0.05$ will be employed.

The cooling water that leaves the first condenser has a high temperature after absorbing the condensation heat. It is employed to preheat the intake seawater, which is then further heated by hot water from Tank 1. When the water temperature in Tank 1 is higher than the desired heating temperature, a portion of water leaving HEX 2 is directed back to the heat exchanger to reduce the hot water flowrate and control the heating temperature, while the rest is mixed with water from Tank 4 and then directed to the solar collectors. These processes are demonstrated in Figure 2(c). Seawater heating processes are described by energy balance equations for $H E X 1$ and HEX 2, while the solar collectors are modelled using the collector efficiency, as summarized in Table 3 and $\underline{\text { Table } 4}$, respectively.

\section{Table 3 Mathematical model for the SLTD system}

\begin{tabular}{|c|c|c|c|}
\hline Component & Equation & Number & Comments \\
\hline \multirow[t]{6}{*}{ Evaporator } & $T_{e l, i+1}=T_{e v, i}+\left(T_{e l, i}-T_{e v, i}\right) \theta_{e, i}$ & (5) & $\begin{array}{l}\text { Temperature change for seawater in } \\
\text { evaporator; } \theta \text { represents the completion } \\
\text { level in the evaporator [28]; }\end{array}$ \\
\hline & $\begin{array}{l}\dot{D}_{v, i} \\
=\dot{m}_{e l, i} \frac{c_{p e l, i}\left(T_{e l, i}-T_{e l, i+1}\right)}{h_{f g e, i}}\end{array}$ & (6) & Evaporation rate; \\
\hline & $\dot{m}_{e l, i+1}=\dot{m}_{e l, i}-\dot{D}_{v, i}$ & (7) & Seawater mass balance; \\
\hline & $\dot{m}_{e l, i+1} X_{l, i+1}=\dot{m}_{e l, i} X_{l, i}$ & (8) & Salt balance; \\
\hline & $T_{e l, 1}=T B T$ & (9) & Inlet condition for evaporator; \\
\hline & $T_{e l, n+1}=T_{s w, o}$ & (10) & Outlet condition for evaporator; \\
\hline \multirow[t]{7}{*}{ Condenser } & $T_{c l, i}=T_{c v, i}-\left(T_{c v, i}-T_{c l, i+1}\right) \theta_{c, i}$ & (11) & $\begin{array}{l}\text { Temperature change for cooling water in } \\
\text { condenser; } \theta \text { represents the completion } \\
\text { level in the condenser [28]; }\end{array}$ \\
\hline & $T_{c v, i}=T_{e v, i}-B P E-T_{l o s s}$ & (11) & $\begin{array}{l}\text { Temperature drop due to pressure drop } \\
\text { across the demister and boiling point } \\
\text { elevation; }\end{array}$ \\
\hline & & & \\
\hline & $=\dot{m}_{c l, i} \frac{{ } \frac{c_{p c l, i}\left(T_{c l, i}-T_{c l, i+1}\right)}{h_{f g c, i}}}{h_{f}}$ & (12) & Condensation rate; \\
\hline & $\dot{m}_{c l, i}=\dot{m}_{c l, i+1}+\dot{D}_{v, i}$ & (13) & Cooling water mass balance; \\
\hline & $T_{c l, n+1}=T_{c w, i n}$ & (14) & Inlet condition for condenser; \\
\hline & $T_{c l, 1}=T_{c w, o}$ & $(15)$ & Outlet condition for condenser; \\
\hline
\end{tabular}




\begin{tabular}{|c|c|c|c|}
\hline & $T_{c v, i}=T_{e v, i}-B P E_{i}-T_{l o s s, i}$ & $(16)$ & $\begin{array}{l}\text { Vapor temperature drop from evaporator } \\
\text { to condenser; }\end{array}$ \\
\hline \multirow[t]{3}{*}{$H E X 1$} & $\dot{Q}_{R}=\dot{m}_{s w, i n} c_{p, s w}\left(T_{s w, r}\right.$ & \multirow{3}{*}{$(17)$} & \multirow{3}{*}{$\begin{array}{l}\text { Recovery of condensation heat from the } \\
\text { cooling water for seawater preheating; } \\
C_{\min } \text { is the minimum of } \dot{m}_{s w, i n} c_{p, s w} \text { and } \\
\dot{m}_{c w, o} c_{p, c w} \text {; }\end{array}$} \\
\hline & $\begin{array}{c}\left.-T_{s w, i n}\right) \\
=\dot{m}_{c w, o} c_{p, c w}\left(T_{c l, o}-T_{c l, r}\right)\end{array}$ & & \\
\hline & $=\varepsilon C_{\min }\left(T_{c l, o}-T_{s w, i n}\right)$ & & \\
\hline \multirow[t]{3}{*}{ HEX 2} & $\dot{Q}_{h}=\dot{m}_{s w, i n} c_{p, s w}(T B T$ & \multirow{3}{*}{ (18) } & \multirow{3}{*}{$\begin{array}{l}\text { Heating seawater to the desired } \\
\text { temperature using collected solar energy; } \\
C_{\min } \text { is the minimum of } \dot{m}_{s w, i n} c_{p, s w} \text { and } \\
\dot{m}_{h} c_{p, h} ;\end{array}$} \\
\hline & $\begin{array}{r}\left.-T_{s w, r}\right) \\
=\dot{m}_{h} c_{p, h}\left(T_{h, i}-T_{h, o}\right)\end{array}$ & & \\
\hline & $=\varepsilon C_{\min }\left(T_{h, i}-T_{s w, r}\right)$ & & \\
\hline \multirow{2}{*}{$\begin{array}{l}\text { System } \\
\text { performance }\end{array}$} & $\dot{D}_{v}=\sum \dot{D}_{v, i}$ & (19) & Overall production rate; \\
\hline & $S E C=\frac{\dot{Q}_{h}}{\dot{D}_{v}}$ & $(20)$ & Specific thermal energy consumption; \\
\hline
\end{tabular}

Table 4 Mathematical model for the solar thermal collector

\begin{tabular}{lcl}
\hline Equation & Number & Comments \\
\hline$\eta_{s}=\eta_{0}-a_{1} \frac{T_{s, i n}-T_{a m b}}{I}-a_{2} \frac{\left(T_{s, i n}-T_{a m b}\right)^{2}}{I}$ & $(21)$ & Solar collector efficiency; \\
$\dot{Q}_{s}=\eta_{s} I A_{s}=\dot{m}_{s} c_{p}\left(T_{s, o}-T_{s, i n}\right)$ & $(22)$ & Heat balance for the solar collector; \\
$\frac{\dot{m}_{h, t k}}{\dot{m}_{h}}=\min \left\{\frac{T_{h, i}-T_{h, o}}{T_{t k, 1}-T_{h, o}}, 1\right\}$ & (23) & $\begin{array}{l}\text { Flowrate of hot water from heat storage } \\
\text { tank for seawater heating; }\end{array}$ \\
$T_{s, i n}=\frac{\dot{m}_{h, t} T_{h, o}+\left(\dot{m}_{s}-\dot{m}_{h, t}\right) T_{t k 4, N}}{\dot{m}_{s}}$ & & $\begin{array}{l}\text { Inlet temperature of circulating fluid for } \\
\text { the solar collector; }\end{array}$ \\
\hline
\end{tabular}

The above equations are formulated and solved in the Matlab platform. During the simulation for the longterm system performance, the initial temperatures in the heat storage tanks are assumed first. Then weather data (including solar radiation and ambient temperature) is imported and solar energy collection is calculated. Based on the circulating fluid temperature leaving the solar collectors, the hot water temperatures in the storage tanks are updated. Afterward, the performance of the SLTD system is achieved. The governing equations for the SLTD system are solved using the successive iteration method we developed previously [21, 22]. The productivity is recorded, while the hot water outlet temperature is employed as the input for calculating the solar collector performance of the next time step. The solution procedure is illustrated in Figure 3. 


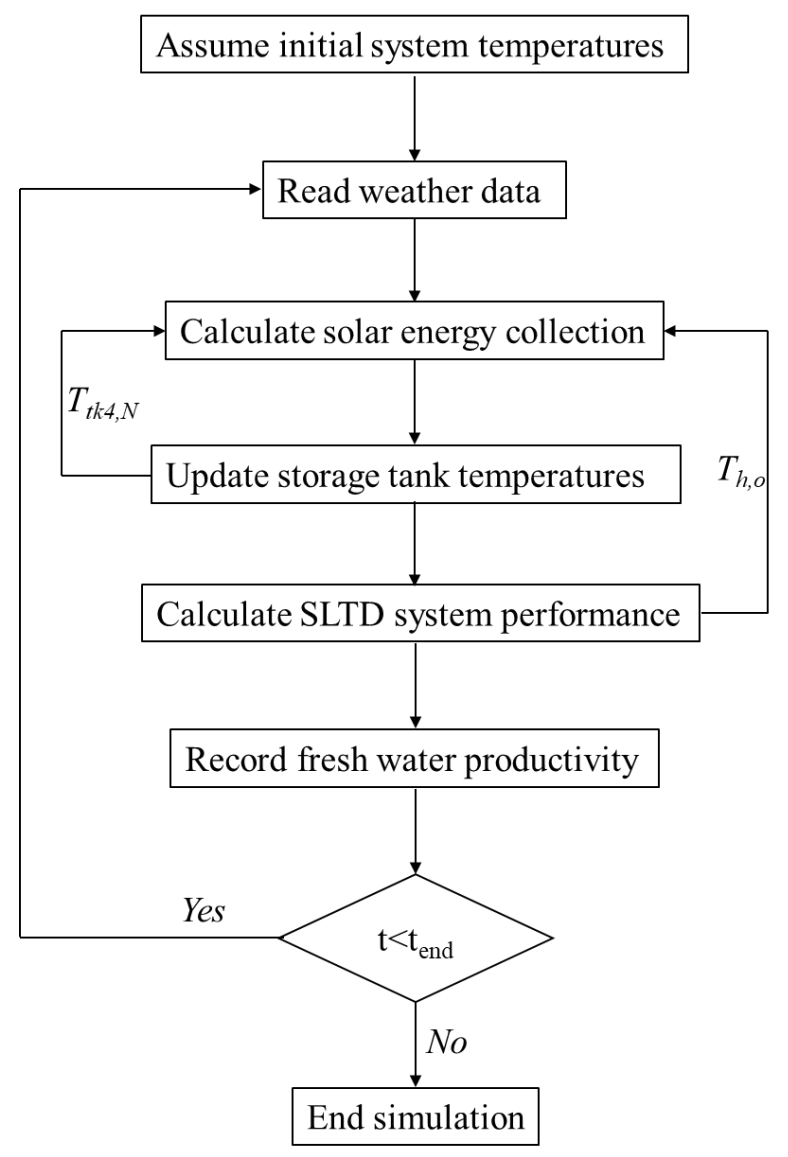

Figure 3 Schematic of the solution algorithm

\section{Model validation}

The mathematical models for the solar collectors and the storage tanks have been well established and validated with extensive experimental data. However, few experimental data on the SLTD system are available in the literature, and no comparison has been made between the experimental and analytical performance of this relatively new technology.

To check the validity of the developed mathematical model for the SLTD system, a pilot plant has been designed and commissioned in the Water Desalination and Reuse Center, King Abdullah University of Science and Technology (WDRC, KAUST). The plant consists of a spray evaporator, a spray condenser, a distillate tank, two water circulation pumps, a vacuum pump, a feed heater, and a plate heat exchanger. During operation, seawater is preheated to the desired temperature and sprayed into the evaporator. A portion of the sprayed seawater is allowed to evaporate by reducing the evaporator pressure, and the produced vapor is condensed by the cooling water in the condenser. The condensate is directed to the distillate tank, where its mass is measured and recorded. The cooling water is cooled down to its initial temperature using chilled water before it is injected back into the condenser. Inline temperature sensors and flowmeters are installed to record the real-time temperatures and flowrates. Signal outputs from these sensors were recorded via an Agilent 34970A Data Acquisition/Switch unit. Details of the measurement instruments are provided in Table 5, while more information on the pilot plant is provided in the Appendix. 
Table 5 Details of measurement instruments

\begin{tabular}{llll}
\hline Sensor & Model & Manufacturer & Range/Uncertainty \\
\hline Thermistor & TJ36-44004-1/8-12 & OMEGA & $0-70{ }^{\circ} \mathrm{C}, \pm 0.1^{\circ} \mathrm{C}$ \\
Paddlewheel flowmeter & ND05-PATAAC-RC & Aichi Tokei Denki & $1.5-20 \mathrm{LPM}, \pm 0.2 \mathrm{LPM}$ \\
Weighing scale & T51XW & OHAUS & $300 \mathrm{~kg}, \pm 50 \mathrm{~g}$ \\
Data logger & $34970 \mathrm{~A}$ & Agilent & $61 / 2$ digits, $0.004 \%$ of reading \\
\hline
\end{tabular}

Several experimental tests were conducted to obtain performance data of the SLTD system. To simulate multistage operation, the seawater outlet temperature for each stage was employed as the inlet temperature for the following evaporator, while the cooling water inlet temperature was regulated to be the same as the outlet temperature of the next condenser. Experimental data were recorded for more than $30 \mathrm{~min}$ at an interval of 3 seconds after the system reached steady-state, and the average values were used for comparison. For model validation, measured temperatures and flowrates for seawater and cooling water were employed as the input to calculate outlet water temperatures and distillate production rates, and the calculated values were compared with the experimental data. Figure 4(a) compares the seawater temperatures at the inlet and outlet of each effect between experimental measurement and model prediction. The seawater inlet temperatures were well controlled to follow the desired values, i.e. inlet temperature in each stage was the same as the outlet temperature of the previous stage. The predicted outlet temperatures in each stage agree well with the measured data, and the average discrepancy is below 1\%. Figure 4(b) presents a comparison of freshwater productivity in each stage. The predicted productivity values adhere closely to the experimental measurement with an average discrepancy of $1 \%$. The discrepancies are mainly attributed to the measurement uncertainties of the sensors, especially the flowmeters. Considering perfect agreement between experiment and simulation for both temperatures and productivity, the developed model can be concluded to have excellent prediction capability.
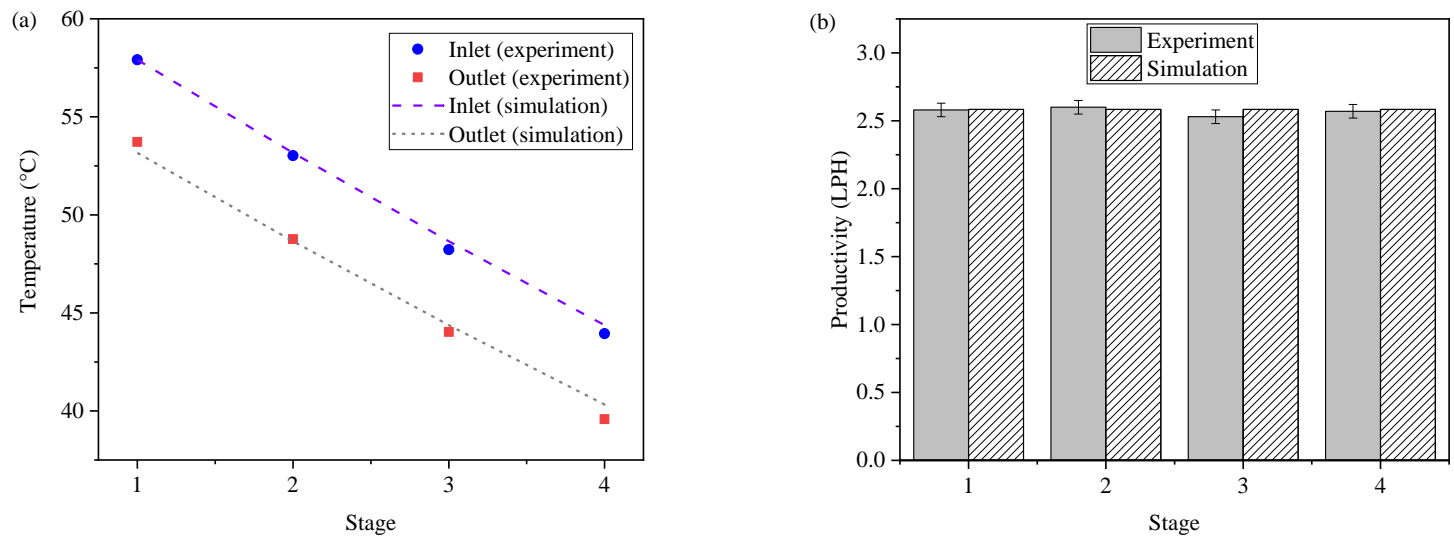

Figure 4 Comparison of experimental and simulation results for a 4-stage system with feed and cooling water flowrates of 5.6 LPM: (a) seawater temperatures at each stage, and (b) production rate; 


\section{Energetic performance}

After validating the mathematical model, it is employed to evaluate the performance of the proposed solar desalination system. The meteorological data of Makkah, Saudi Arabia ( $21^{\circ} 38^{\prime}$ N, 39 $39^{\circ} 86^{\prime}$ E) is used as an input. A solar thermal plant with a collector area of $360 \mathrm{~m}^{2}$ is employed to drive a 10-stage SLTD system, and four heat storage tanks are incorporated for thermal energy storage to enable counter-clock operation. Flat-plate solar thermal collectors are selected to reduce costs. The collectors are oriented to face the south and tilted by $21^{\circ}$ with respect to the horizontal axis. Water is used as the circulating fluid and the heat storage medium due to its outstanding thermal properties.

A parametric study is firstly conducted on the SLTD system under the steady-state condition to optimize the heating temperature, and then dynamic simulations are carried out for the solar desalination system to evaluate its long-term performance. A seawater flowrate of $1.5 \mathrm{~kg} / \mathrm{s}$ will be used as an initial design, along with a tank diameter of $2 \mathrm{~m}$. The effects of the seawater flowrate and the tank dimension will be evaluated subsequently. Table 6 summarizes the major system parameters.

Table 6 Plant parameters and input data for Solar-SLTD system

\begin{tabular}{lll}
\hline Location & Latitude $\left(^{\circ}\right)$ & 21.3891 \\
& Longitude $\left({ }^{\circ}\right)$ & 39.8579 \\
\hline Collector & Flat-plate solar collector & \\
& Total collector area $\left(\mathrm{m}^{2}\right)$ & 360 \\
& Intercept efficiency & $0.822^{[30]}$ \\
& First-order loss coefficient $\left(\mathrm{W} / \mathrm{m}^{2}-\right.$ & $2.77^{[30]}$ \\
& $\mathrm{K})$ & \\
& Second-order loss coefficient & $0.017^{[30]}$ \\
& $\left(\mathrm{W} / \mathrm{m}^{2}-\mathrm{K}\right)$ & \\
& Tilt angle $\left({ }^{\circ}\right)$ & 21 \\
& Circulating fluid flowrate, $\mathrm{kg} / \mathrm{s}$ & 2 \\
\hline Storage tank & Tank diameter, D $(\mathrm{m})$ & $1.5-2.2$ \\
& Tank height, H & $2.5 \times \mathrm{D}$ \\
& Heat loss coefficient $\left(\mathrm{W} / \mathrm{m}^{2}-\mathrm{K}\right)$ & $1^{[24,25]}$ \\
\hline Desalination system & Number of operating stages & 10 \\
& Seawater flowrate $(\mathrm{kg} / \mathrm{s})$ & $1-2$ \\
& Seawater salinity $(\mathrm{g} / \mathrm{kg})$ & 35 \\
& Cooling water flowrate $(\mathrm{kg} / \mathrm{s})$ & $0.9-1.9$ \\
& Heating temperature $\left({ }^{\circ} \mathrm{C}\right)$ & $55-75$ \\
\hline
\end{tabular}

Figure 5 shows the steady-state performance of the SLTD system under different heating and cooling (ambient) temperatures. Productivity is proportional to the heat source temperature while inversely correlated to the ambient temperature. The reason is that there is no heat input to seawater in the evaporatorcondenser stages, and the temperature difference between the seawater and the cooling water is the only driving force for evaporation. Therefore, productivity is proportional to the temperature difference between the seawater and the cooling water. Such a feature will favor counter-clock operation in the evening since the drop of hot water temperatures can be partially compensated by a lower ambient temperature. The specific energy consumption is decreased under a higher heat source temperature and a lower cooling water temperature, which is a result of improved heat recovery. Therefore, a higher heating temperature is preferable to promote system performance. However, the potential for scaling and fouling is also increased 
when the seawater temperature is higher. To mitigate the tendency of scaling and fouling, the maximum heating temperature in this study will be limited to $75^{\circ} \mathrm{C}$.
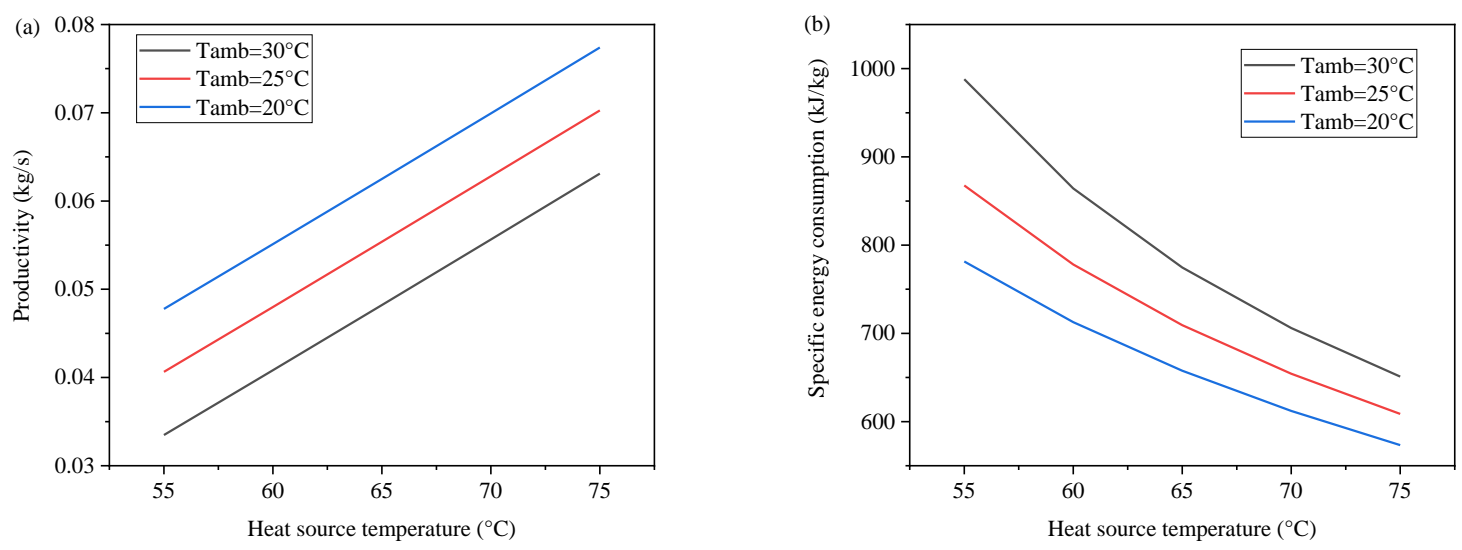

Figure 5 Steady-state performance of the spray-assisted low-temperature desalination system under different heat source/cooling water temperatures: (a) productivity and (b) specific energy consumption. Seawater and cooling water flowrates are $1 \mathrm{~kg} / \mathrm{s}$ and $0.95 \mathrm{~kg} / \mathrm{s}$, respectively

Figure 6(a) shows the solar radiation and ambient temperature for a typical sunny day (Mar 25). Solar radiation lasts from 6:00 am to 6:00 pm, and the peak value occurs at noon. The ambient temperature profile lags behind the solar radiation by two hours, and the maximum and minimum temperatures $\left(21{ }^{\circ} \mathrm{C}\right.$ and $36{ }^{\circ} \mathrm{C}$, respectively) are observed at 2:00 pm and 5:00 am, respectively. The daily fluctuation of ambient temperature is about $15^{\circ} \mathrm{C}$, which is a result of the high solar intensity. Such a climatic profile has a significant impact on solar energy collection and utilization. The temperatures for the storage tanks and the hourly productivity are plotted in Figure 6(b). It should be noted that fluid temperatures are stratified inside each tank, and the values at the top of the tanks are plotted here as a representative. Tank 1 has the highest temperature and its profile follows exactly the trend of solar radiation. The hot water temperatures decrease in the subsequent tanks, with Tank 4 having the lowest temperature. The temperature stratification is attributed to effective thermal management, and it helps to improve freshwater production since a higher heating temperature is preferable for the SLTD system. The scattered line in Figure 6(b) shows the hourly average productivity. It can be seen from the figure that the system can sustain a 24-hour water production due to its heat storage capability. The production rate increases markedly in the morning from 8:00 am to 12:00 pm due to increasing solar radiation and higher heat source temperatures. Afternoon its value starts to drop, but the variation is insignificant because the drop of solar radiation is compensated by a lower ambient temperature. A significant productivity drop is only observed between 6:00 am and 8:00 am when the ambient temperature starts to get higher while the solar radiation is still low. 

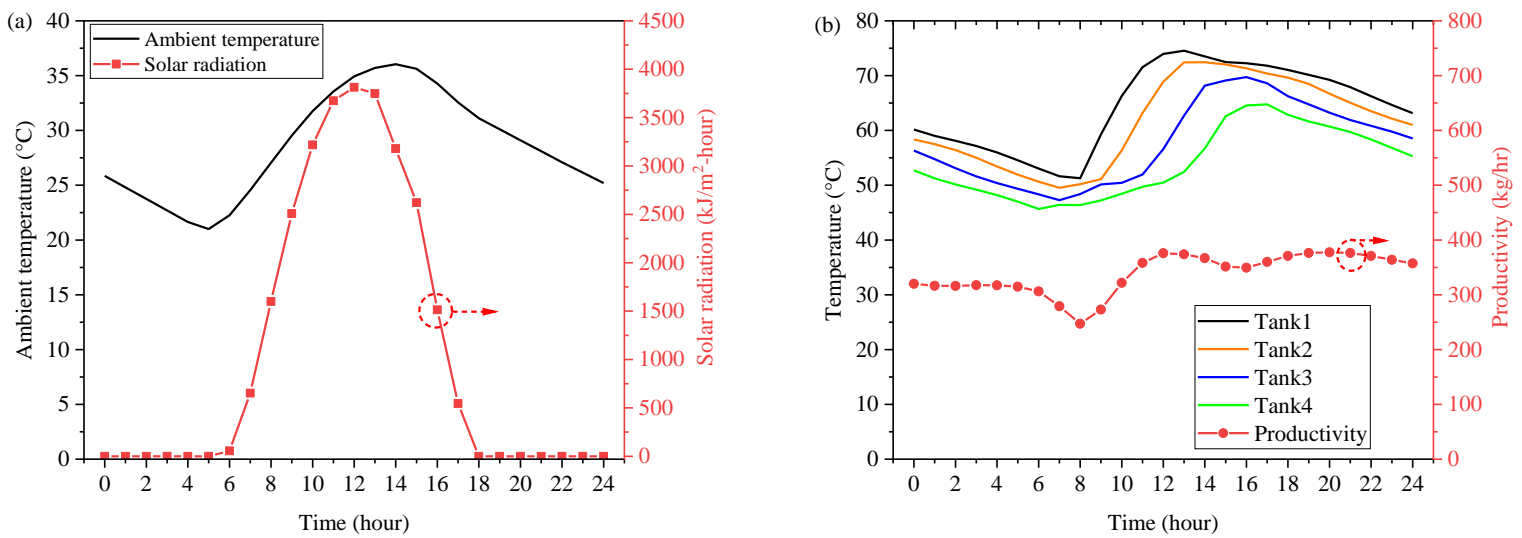

Figure 6 (a) Solar radiation and ambient temperature for a typical sunny day, and (b)

\section{Instantaneous tank temperatures and productivity}

Table 7 summarizes the annual performance of the proposed solar desalination system under the climatic condition of Makkah. The data for each month is based on evaluating the system performance at one-hour interval, and the storage tanks are assumed to have a uniform temperature of $75{ }^{\circ} \mathrm{C}$ at the beginning of the simulations. The solar collectors can sustain a high efficiency of more than $60 \%$ throughout the year, which is a combined result of (a) high solar intensity in Makkah, (b) superior performance of the solar thermal collectors, and (c) effective thermal management. Consequently, solar energy can be effectively collected and utilized. As shown in the $5^{\text {th }}$ and $6^{\text {th }}$ columns, both the collected solar energy and the heat input to the desalination system follow the same trend as the solar radiation: the values are high from March to May as well as for October, while February, June, and December have much smaller numbers. The monthly average productivity also follows the same trend for most of the months, except for October and November. October has higher solar radiation, but the freshwater production rate is observed to be slightly lower than that of November, which is a result of a higher ambient temperature.

Table 7 Annual performance of the proposed solar-driven SLTD system under the climatic condition of Makkah

\begin{tabular}{cccccccc}
\hline Month & $\begin{array}{c}\text { Solar } \\
\text { radiation } \\
\mathbf{k J} / \mathbf{m}^{2} \mathbf{- h r}\end{array}$ & $\begin{array}{c}\text { Ambient } \\
\text { temperature } \\
{ }^{\mathbf{C}}\end{array}$ & $\begin{array}{c}\text { Collector } \\
\text { efficiency } \\
\mathbf{\%}\end{array}$ & $\begin{array}{c}\text { Collected } \\
\text { heat } \\
\mathbf{k W h}\end{array}$ & $\begin{array}{c}\text { Desalination } \\
\text { heat input } \\
\mathbf{k W h}\end{array}$ & $\begin{array}{c}\text { Heat loss } \\
\mathbf{k W h}\end{array}$ & $\begin{array}{c}\text { Productivity } \\
\mathbf{m}^{\mathbf{3}} \mathbf{m} \mathbf{m o n t h}\end{array}$ \\
\hline Jan & 183.09 & 26.2 & 66.44 & 45429.02 & 44164.67 & 2733.53 & 205.21 \\
Feb & 177.21 & 25.0 & 64.77 & 43074.09 & 40769.82 & 2730.34 & 202.17 \\
Mar & 219.75 & 27.5 & 63.27 & 51865.64 & 47861.01 & 3649.26 & 256.78 \\
Apr & 220.12 & 30.5 & 60.18 & 49941.36 & 46790.50 & 3969.50 & 256.05 \\
May & 209.25 & 33.8 & 62.20 & 48933.69 & 46368.27 & 3489.04 & 236.23 \\
Jun & 182.56 & 35.1 & 65.50 & 44402.33 & 42304.55 & 2716.77 & 196.60 \\
Jul & 183.89 & 35.5 & 65.11 & 44521.64 & 42520.55 & 2779.57 & 194.90 \\
Aug & 193.58 & 35.0 & 64.77 & 46699.73 & 43850.21 & 2962.42 & 208.50 \\
Sep & 205.65 & 33.7 & 62.67 & 48252.29 & 44695.06 & 3484.13 & 226.41 \\
Oct & 238.38 & 31.4 & 58.04 & 52263.95 & 48143.97 & 4967.78 & 261.56 \\
Nov & 214.69 & 28.0 & 61.74 & 49943.52 & 47512.81 & 3967.65 & 266.34
\end{tabular}


Figure 7 schematically shows the annual average energy flow of the proposed solar desalination system. The annual solar radiation falling on the collector surface is $2400 \mathrm{kWh} / \mathrm{m}^{2}$, and $65.8 \%$ of them are collected and converted into heat. $4.6 \%$ of the solar energy is lost to the ambient after being collected, while the majority is effectively utilized for seawater heating. In the SLTD system, the heat input from the storage tanks accounts for only a small portion of the energy source for evaporation, and a majority $(\sim 70 \%)$ of the evaporation heat comes from the recovered condensation heat. The annual freshwater yield is $7.5 \mathrm{~m}^{3}$ for 1 $\mathrm{m}^{2}$ collector, and the specific energy consumption for desalination is $725 \mathrm{~kJ} / \mathrm{kg}$. These results derived based on annual performance will enable a quick estimation of the component sizes in the future design.

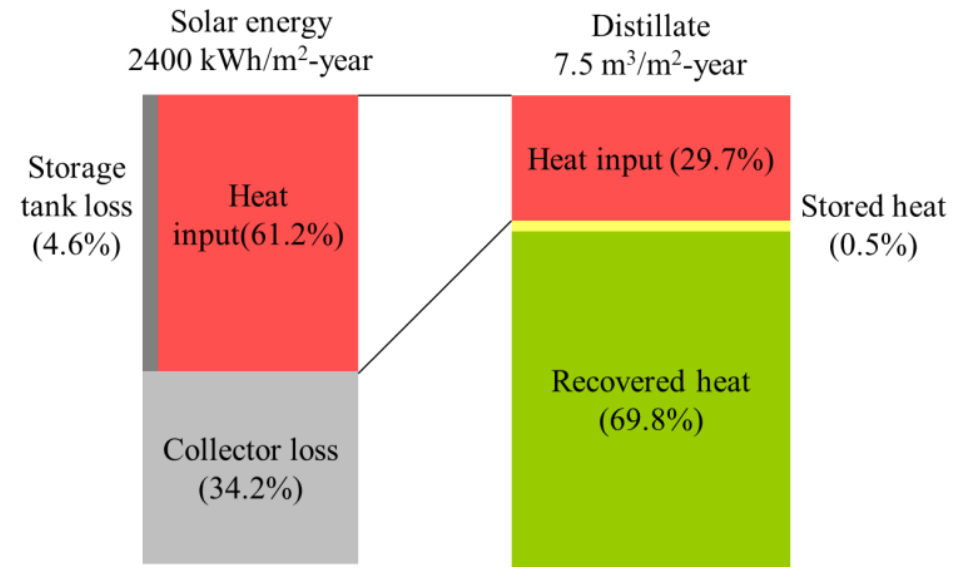

Figure 7 Annual energy analysis for the proposed solar-driven SLTD system

Figure 8 shows the volume of freshwater in the storage tank. Initial water storage is assumed to be $90 \mathrm{~m}^{3}$, and daily water consumption is $7.3 \mathrm{~m}^{3}$, which is equal to the daily average productivity of the proposed system. As shown in the figure, the amount of freshwater in the storage tank increases during two periods, i.e. March to May and August to November. These are the months when water productivity is higher than the daily consumption, as revealed previously in Table 7. For the rest of the year, productivity is smaller than the consumption, and the volume of the stored water decreases. The minimum value of water storage occurs at the end of August. Its value is larger than zero $\left(0.72 \mathrm{~m}^{3}\right)$, indicating that the system can provide an uninterrupted water supply for the whole year. Meanwhile, the peak value of $130.5 \mathrm{~m}^{3}$ is observed at the end of November, which represents the minimum requirement of storage tank volume. 


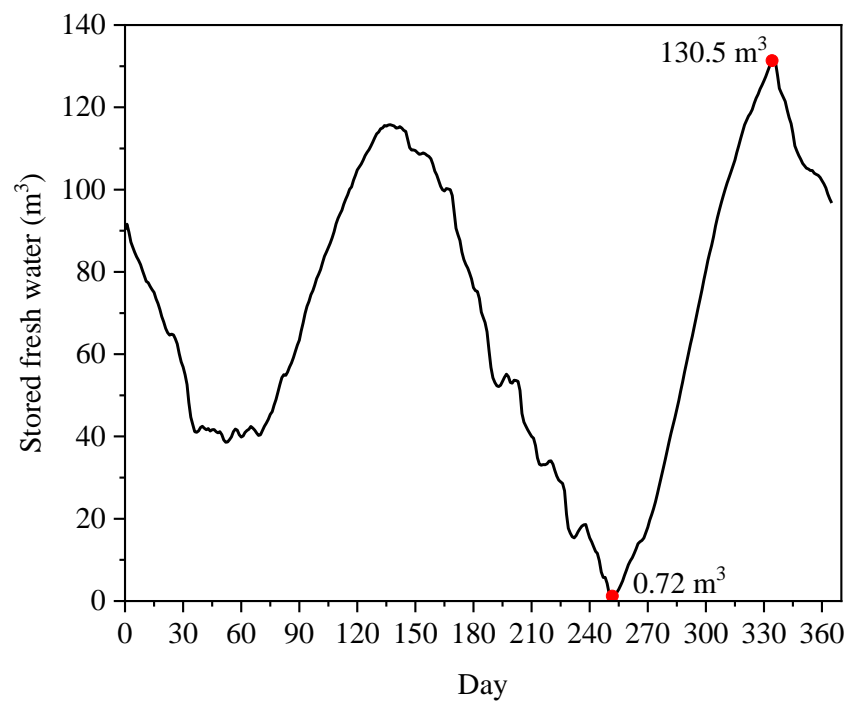

\section{Figure 8 Annual profile of the stored freshwater}

The productivity for unit solar collector area is much higher than other solar desalination systems operating under similar meteorological conditions, as summarized in Table 8. The reasons include (a) the employment of high-efficiency solar collectors that boost solar energy collection, (b) effective recovery of condensation heat by the multi-stage configuration to reduce specific thermal energy consumption, and (c) implementation of temperature regulation, which not only boosts thermal collector efficiency but also improves the SLTD productivity.

Table 8 Comparison of productivity with other solar desalination systems

\begin{tabular}{|c|c|c|c|c|c|}
\hline $\begin{array}{c}\text { Desalination } \\
\text { technology }\end{array}$ & Solar collector & Heat storage & City & $\begin{array}{l}\text { Productivity } \\
\left(\mathrm{m}^{3} / \text { year-m } \mathbf{m}^{2}\right)\end{array}$ & Source \\
\hline Single-stage SLTD & Flat-plate collector & N.A. & Tanta, Egypt & $3.29^{\mathrm{a}}$ & {$[18]$} \\
\hline Single-stage SLTD & Flat-plate collector & Single tank & Singapore & 1.44 & [19] \\
\hline $\begin{array}{l}\text { Multi-stage flash } \\
\text { desalination (MSF) }\end{array}$ & $\begin{array}{l}\text { Parabolic trough } \\
\text { collectors }\end{array}$ & $\begin{array}{l}\text { Stratified } \\
\text { solar pond }\end{array}$ & Sharjah, UAE & $0.58-0.66$ & [9] \\
\hline Multi-stage SLTD & $\begin{array}{l}\text { Flat-plate solar } \\
\text { collector }\end{array}$ & $\begin{array}{l}\text { Storage tanks } \\
\text { with thermal } \\
\text { management }\end{array}$ & $\begin{array}{l}\text { Makkah, } \\
\text { Saudi Arabia }\end{array}$ & 7.5 & $\begin{array}{l}\text { Current } \\
\text { study }\end{array}$ \\
\hline
\end{tabular}

a. Calculated from peak value measured at noon. The actual long-term value will be less than $25 \%$ of the peak value;

According to the results of the annual energy analysis, it is obvious that the system performance can be improved by (a) promoting solar energy collection, (b) reducing the specific energy consumption in the SLTD system, and (c) minimizing heat losses to the ambient. However, these conditions conflict with each other and cannot be achieved simultaneously. For example, more solar energy collection will result in higher hot water temperatures. The energy efficiency of the SLTD system will improve accordingly, while the heat losses to the ambient will also increase. Therefore, the optimal system design will be subjected to the best trade-offs among these three factors, which are controlled by the feed seawater flowrate and the storage tank dimension. To optimize the proposed system, an investigation of these two variables is presented below. 
Figure 9(a) shows the annual average productivity as a function of the feed flowrate. The productivity first increases when the feed flowrate is increased from 1 to $1.7 \mathrm{~kg} / \mathrm{s}$, and its value starts to drop when further increasing the feed flowrate. An increase of the feed flowrate will extract more heat from the storage tanks, leading to lower tank temperatures. The reduction of tank temperatures has two conflicting effects. Firstly, it will lead to a higher collector efficiency and promote solar energy collection, as shown in Figure 9(b). However, the specific energy consumption of the desalination process will suffer due to less complete heat recovery, as discussed previously. The peak value of productivity at a feed flowrate of $1.7 \mathrm{~kg} / \mathrm{s}$ is the result of the trade-offs between these two conflicting effects.
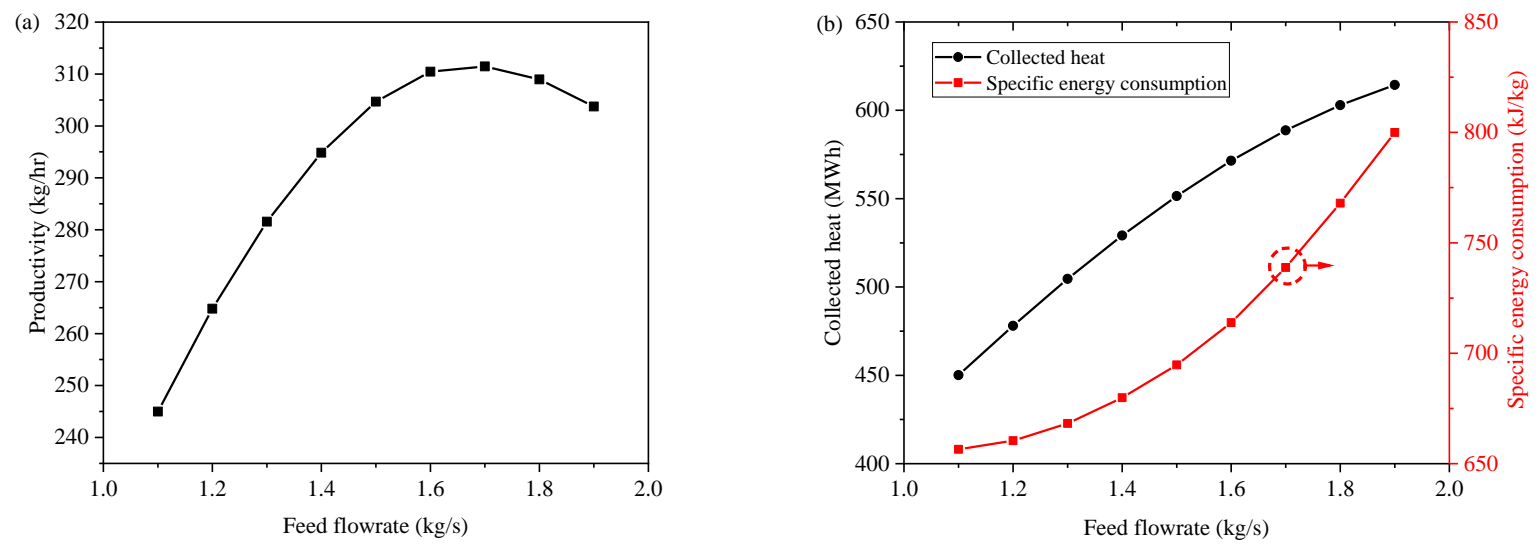

Figure 9 Effect of feed flowrate on (a) productivity and (b) solar collector efficiency and desalination efficiency

Similar to the effect of the feed flowrate, there is an optimal diameter for the storage tank that maximizes productivity, which is around $1.9 \mathrm{~m}$, as presented in Figure 10(a). A larger tank leads to a lower fluid temperature and promotes solar collector efficiency, as can be seen in Figure 10(b). Meanwhile, the surface area is also larger, and more heat loss will occur. The optimal dimension of the storage tank is the compromise between solar energy collection and heat losses.
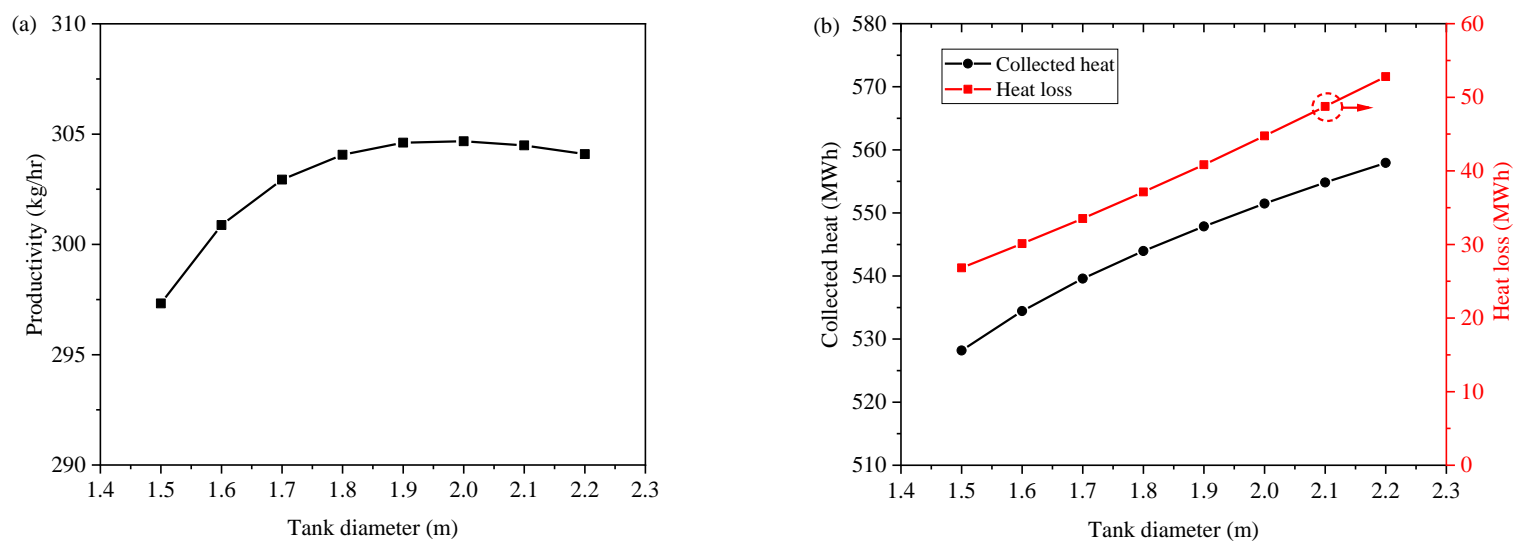

Figure 10 Effect of storage tank diameter on (a) productivity (b) collector performance and storage tank heat loss 


\section{Economic analysis}

Based on the above analyses, a solar-driven SLTD plant with a capacity of $100,000 \mathrm{~m}^{3} /$ day is designed and evaluated economically. According to the long-term performance data, the required solar collector area is calculated first. Then the corresponding initial and operational costs are obtained. The electricity consumption of the feed pumps as well as the vacuum pump is assumed to be provided by the grid, and the cost is estimated separately. The economic analysis is summarized in Table 9. As clearly shown in the table, the SLTD system is cost-effective, making its integration with solar thermal plants economically viable. The final cost for freshwater is $\$ 1.29 / \mathrm{m}^{3}$. As a comparison, the initial and operational costs for other thermal desalination processes are several times higher than the SLTD system [13], which will lead to much higher desalination costs $\left(\$ 4-10 / \mathrm{m}^{3}\right.$ for membrane distillation [31], $\$ 2-2.5 / \mathrm{m}^{3}$ for MED [31] and $>\$ 3 / \mathrm{m}^{3}$ for MSF [9]).

\section{Table 9 Economic analysis for solar-driven SLTD}

\begin{tabular}{|c|c|}
\hline Parameter & Value \\
\hline Plant capacity, $\mathrm{m}^{3} /$ day & 100000 \\
\hline Initial cost for SLTD system, $\$ /\left(\mathrm{m}^{3} /\right.$ day $)$ & $1000^{\text {a }}$ \\
\hline Cost of SLTD plant, \$ & $1.00 \times 10^{8}$ \\
\hline Required solar collectors area, $\mathrm{m}^{2}$ & $4.87 \times 10^{6 b}$ \\
\hline Cost of collector \& tanks, $\$$ & $3.8 \times 10^{8}$ \\
\hline Lifespan, years & 30 \\
\hline Interest rate & $5 \%$ \\
\hline $\mathrm{CRF}$ & 0.07 \\
\hline CAPEX, \$/year & $3.12 \times 10^{7}$ \\
\hline Capex, $\$ / \mathrm{m}^{3}$ & 0.85 \\
\hline O\&M cost of SLTD, \$/year & $2.60 \times 10^{6 c}$ \\
\hline Feed pumping cost, \$/year & $1.31 \times 10^{7 \mathrm{~d}}$ \\
\hline Opex, $\$ / \mathrm{m}^{3}$ & 0.43 \\
\hline Total cost, \$/year & $4.69 \times 10^{7}$ \\
\hline Total unit cost, $\$ / \mathrm{m}^{3}$ & 1.29 \\
\hline
\end{tabular}

a. Data obtained from our earlier study [13];

b. Calculated from the annual simulation results of $7.5 \mathrm{~m}^{3} / \mathrm{m}^{2}$-year;

c. Assumed to be $30 \%$ of the initial cost;

d. Based on an overall head loss of $30 \mathrm{~m}$ in both evaporators and condensers;

\section{Conclusions}

In this study, a solar-driven spray-assisted low-temperature desalination system has been investigated. A mathematical model has been developed to obtain its thermodynamic performance under dynamic solar irradiance conditions. The model demonstrates excellent prediction capability after comparison with experimental data. Applying the validated model, the annual performance of the proposed system is 
evaluated using the meteorological data of Makkah, Saudi Arabia. Key results emerged from the study include:

(1) The proposed solar-driven SLTD system can provide counter-clock freshwater production, regardless of the intermittency of solar radiation. The production rate remains stable in the evening due to effective thermal management;

(2) Under the climatic conditions of Makkah, the collectors can sustain its efficiency at more than $60 \%$ for all the seasons, enabling the effective utilization of solar energy for desalination. The freshwater productivity adheres to the trend of solar radiation;

(3) The yearly solar collector efficiency is observed to be $65.8 \%$, yielding an annual distillation production of $7.5 \mathrm{~m}^{3}$ for per $\mathrm{m}^{2}$ collector area, and the specific energy consumption for desalination is $725 \mathrm{~kJ} / \mathrm{kg}$;

(4) Under a fixed solar collector area of $360 \mathrm{~m}^{2}$, the annual productivity is maximized when the feed flowrate is $1.7 \mathrm{~kg} / \mathrm{s}$. A lower feed flowrate will result in higher storage tank temperatures and affect the solar collector efficiency, while a higher feed flowrate results in lower tank temperatures and decreases the efficiency of the SLTD system;

(5) There is also an optimal storage tank dimension that maximizes productivity, and the value is around $1.9 \mathrm{~m}$, which is a result of the compromise between a lower solar collector efficiency and more heat losses to the ambient;

(6) The unit water cost of the proposed solar desalination system is $\$ 1.29 / \mathrm{m}^{3}$, which is much lower than other thermal desalination systems driven by solar energy.

The derived results provide a robust and reliable basis for the design and evaluation of the solar-driven SLTD system. The annual productivity and energy efficiency will allow a quick estimation of the component dimensions, and the results of the parametric study help to maximize the productivity in actual operation. However, the analysis is based on the specific conditions (climatic data, cost, etc) of Saudi Arabia, and the performance of such a system in other regions remains unknown. It is expected that the performance of the proposed system in different regions will be evaluated in the future. Another limitation of the current study is that it only covers energetic analyses based on the First-law of thermodynamics, which is unable to capture the essence and causes of the imperfection inside the system. To enable a more in-depth understanding of the process irreversibility, a Second-law analysis will be conducted in our future research.

\section{Nomenclature}

$\begin{array}{ll}B P E & \text { Boiling point elevation, }{ }^{\circ} \mathrm{C} \\ C & \text { Heat capacity, } \mathrm{W} /{ }^{\circ} \mathrm{C} \\ C A P E X & \text { Capital expenditures, } \$ / \text { year } \\ C R F & \text { Capital recovery factor } \\ m & \text { Mass, kg } \\ T & \text { Temperature, }{ }^{\circ} \mathrm{C} \\ A & \text { Area, } \mathrm{m}^{2} \\ B P E & \text { Boiling point elevation, }{ }^{\circ} \mathrm{C} \\ c_{p} & \text { Specific heat, } \mathrm{J} / \mathrm{kg}^{\circ}{ }^{\circ} \mathrm{C} \\ D & \text { Distillate, } \mathrm{kg} \\ H & \text { Height, } \mathrm{m}\end{array}$




$\begin{array}{ll}h_{f g} & \text { Latent heat of vaporization, } \mathrm{J} / \mathrm{kg} \\ I & \text { Solar radiation, } \mathrm{W} / \mathrm{m}^{2} \\ k & \text { Thermal conductivity } \\ \text { Opex } & \text { Operating expenditure, } \$ / \text { year } \\ Q & \text { Heat, J } \\ S E C & \text { Specific energy consumption, } / \mathrm{kg} \\ T B T & \text { Top brine temperature, }{ }^{\circ} \mathrm{C} \\ U & \text { Heat transfer coefficient, } \mathrm{W} / \mathrm{m}^{2}-{ }^{\circ} \mathrm{C}\end{array}$

Greek letters

$$
\varepsilon
$$

$\Delta$

$\eta$

$\theta$

\author{
Heat exchanger effectiveness \\ Difference \\ Efficiency, \% \\ Non-dimensional temperature difference
}

$\begin{array}{ll}\begin{array}{ll}\text { Subscripts } \\ \text { amb }\end{array} & \text { Ambient } \\ b i & \text { In-flow at the bottom layer of the tank } \\ b o & \text { Outflow at the bottom layer of the tank } \\ c l & \text { Liquid in condenser side } \\ c v & \text { Vapor in condenser side } \\ c w & \text { Cooling water } \\ e l & \text { Liquid in evaporator side } \\ e v & \text { Vapor in evaporator side } \\ H & \text { Heating } \\ h & \text { Heating } \\ i & \text { Stage/layer number } \\ i n & \text { Inlet } \\ l & \text { Liquid phase } \\ l o s s & \text { Heat loss; temperature loss } \\ n & \text { Number of stages for desalination system } \\ N & \text { Number of layers in the heat storage tanks } \\ o & \text { Outlet } \\ R & \text { Heat recovery } \\ s & \text { Solar collector } \\ s w & \text { Seawater } \\ t i & \text { In-flow at the top layer of the tank } \\ t k & \text { Tank } \\ t o & \text { Outflow at the top layer of the tank } \\ v & \text { Vapor phase } \\ & \end{array}$

\title{
Acknowledgement
}


This research was supported by the Water Desalination and Reuse Center (WDRC), King Abdullah University of Science and Technology (KAUST).

\section{Appendix}

Figure A1 shows the schematic of the single-stage SLTD experimental setup. The setup includes a spray evaporator, a spray condenser, a distillate tank, two water circulation pumps, a vacuum pump, a feed heater and a plate heat exchanger. Both the evaporators and condensers are hollow vessels made of stainless steels with a dimension of $\mathrm{D} 300 \mathrm{~mm} \times \mathrm{H} 800 \mathrm{~mm}$. They are covered with nitrile rubber insulation materials to reduce heat losses. The connections between the chambers and the pipelines are sealed with O-rings to prevent leakage of air into the system.

During operation, seawater is preheated to the desired temperature using the heater and then sprayed into the evaporator. The produced vapor is directed to the condenser to be condensed by the cooling water. A wire-mesh demister is placed in between to prevent droplet entrainment. The cooling water temperature is regulated in a heat exchanger using chilled water.

Figure A2 presents a pictorial view of the system components, and Table A1 is a summary of the measurement uncertainties. The uncertainties of directly measured parameters were determined by the accuracies of the sensors, while those incurred from indirectly measured parameters were estimated via the error propagation method [32]

$$
\Delta y=\left[\sum_{i=1}^{n}\left(\frac{\partial f}{\partial x_{i}}\right)^{2}\left(\Delta x_{i}\right)^{2}\right]^{1 / 2}
$$

where $\Delta x$ is the absolute uncertainty of the directly measured parameters, $n$ is the total number of directly measured parameters, $f$ is the function of the independent variables and $\Delta y$ is the absolute uncertainty of the indirectly measured parameters.

Table Al Measurement uncertainties of different parameters

\begin{tabular}{lllll}
\hline Variable & Description & Nominal value & $\begin{array}{l}\text { Absolute } \\
\text { uncertainty }\end{array}$ & $\begin{array}{l}\text { Relative } \\
\text { uncertainty }\end{array}$ \\
\hline$T_{e l}$ & $\begin{array}{l}\text { Seawater inlet } \\
\text { temperature }\end{array}$ & $52{ }^{\circ} \mathrm{C}$ & $\pm 0.1{ }^{\circ} \mathrm{C}$ & $0.2 \%$ \\
$T_{c l}$ & $\begin{array}{l}\text { Cooling water } \\
\text { temperature }\end{array}$ & $48{ }^{\circ} \mathrm{C}$ & $\pm 0.1{ }^{\circ} \mathrm{C}$ & $0.2 \%$ \\
$T_{v}$ & $\begin{array}{l}\text { Saturation vapor } \\
\text { temperature }\end{array}$ & $50{ }^{\circ} \mathrm{C}$ & $\pm 0.1{ }^{\circ} \mathrm{C}$ & $0.2 \%$ \\
$m_{e l}$ & $\begin{array}{l}\text { Seawater flowrate } \\
m_{c l}\end{array}$ & $5.6 \mathrm{LPM}$ & $\pm 0.2 \mathrm{LPM}$ & $3.5 \%$ \\
$D$ & $\begin{array}{l}\text { Cooling water } \\
\text { flowrate }\end{array}$ & $5.6 \mathrm{LPM}$ & $\pm 0.2 \mathrm{LPM}$ & $3.5 \%$ \\
$Q$ & Distillate & $2 \mathrm{~kg}$ & $0.05 \mathrm{~kg}$ & $2.5 \%$ \\
& Heat input & - & - & $2.45 \%$
\end{tabular}




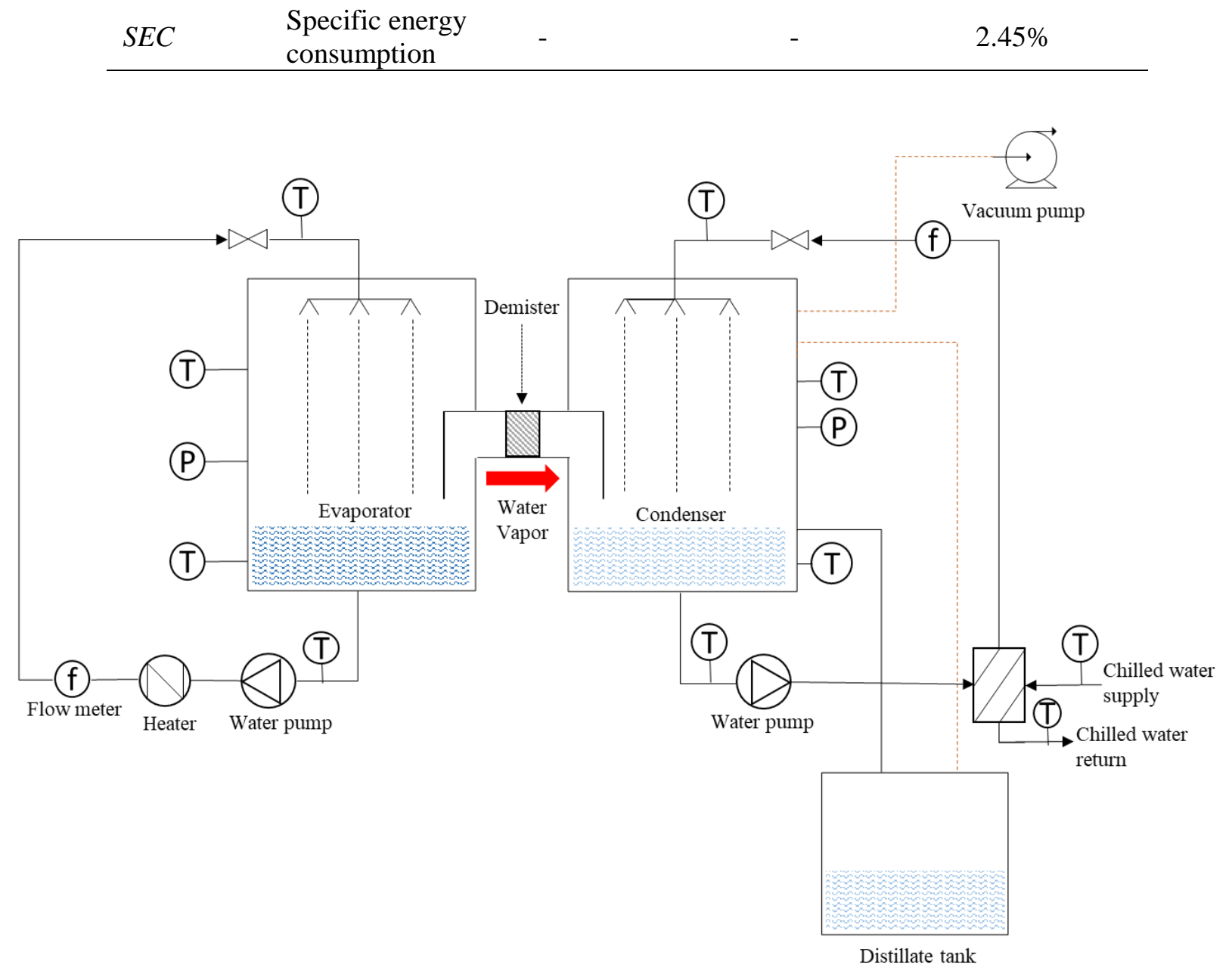

Figure A1 Schematic of the single-stage SLTD experimental setup 

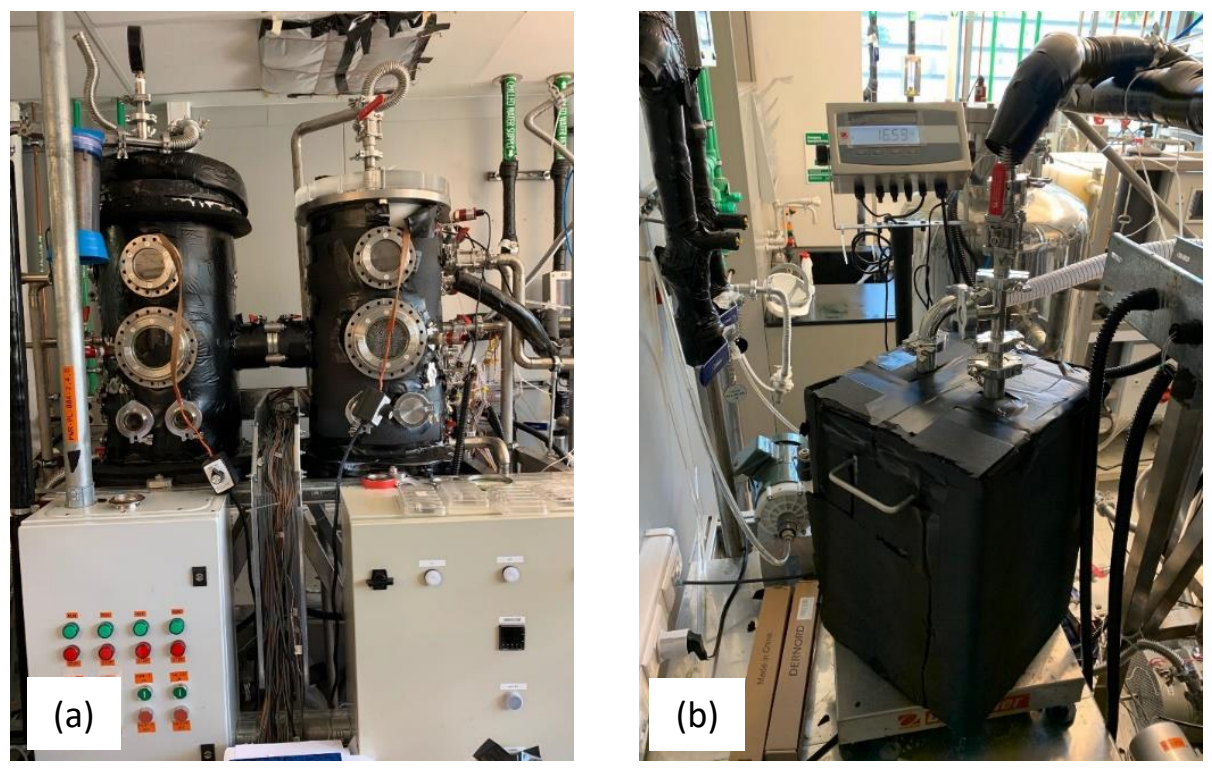

Figure A2 Pictorial view of the system components: (a) evaporator (left), condenser (right) and control panel (down); (b) distillate tank placed atop of a weighing scale

\section{References}

1. Intellegence, G.W., Global Desalination Yearbook 2017-2018. https://www.desalination.com/publications/desalination-report-wdr, 2018.

2. Ghaffour, N., T.M. Missimer, and G.L. Amy, Technical review and evaluation of the economics of water desalination: current and future challenges for better water supply sustainability. Desalination, 2013. 309: p. 197-207.

3. Rahimi, B., A. Christ, K. Regenauer-Lieb, and H.T. Chua, A novel process for low grade heat driven desalination. Desalination, 2014. 351: p. 202-212.

4. Ghaffour, N., S. Lattemann, T. Missimer, K.C. Ng, S. Sinha, and G. Amy, Renewable energydriven innovative energy-efficient desalination technologies. Applied Energy, 2014. 136: p. 11551165 .

5. Mamouri, S.J., H.G. Derami, M. Ghiasi, M. Shafii, and Z. Shiee, Experimental investigation of the effect of using thermosyphon heat pipes and vacuum glass on the performance of solar still. Energy, 2014. 75: p. 501-507.

6. Kasaeian, A., S. Babaei, M. Jahanpanah, H. Sarrafha, A.S. Alsagri, S. Ghaffarian, and W.-M. Yan, Solar humidification-dehumidification desalination systems: A critical review. Energy Conversion and Management, 2019. 201: p. 112129.

7. Manolakos, D., E.S. Mohamed, I. Karagiannis, and G. Papadakis, Technical and economic comparison between PV-RO system and RO-Solar Rankine system. Case study: Thirasia island. Desalination, 2008. 221(1-3): p. 37-46.

8. Lee, J.-G., W.-S. Kim, J.-S. Choi, N. Ghaffour, and Y.-D. Kim, Dynamic solar-powered multistage direct contact membrane distillation system: concept design, modeling and simulation. Desalination, 2018. 435: p. 278-292.

9. Al-Othman, A., M. Tawalbeh, M.E.H. Assad, T. Alkayyali, and A. Eisa, Novel multi-stage flash (MSF) desalination plant driven by parabolic trough collectors and a solar pond: A simulation study in UAE. Desalination, 2018. 443: p. 237-244.

10. Raphael, V.S.P., R. Velraj, and P. Jalihal, Transient analysis of steam accumulator integrated with solar based MED-TVC system. Desalination, 2018. 435: p. 3-22. 
11. Chen, Q. and K.J. Chua, A spray assisted low-temperature desalination technology, in Emerging Technologies for Sustainable Desalination Handbook. 2018, Elsevier. p. 255-284.

12. Chen, Q., M.K. Ja, Y. Li, and K. Chua, Energy, exergy and economic analysis of a hybrid sprayassisted low-temperature desalination/thermal vapor compression system. Energy, 2019. 166: p. 871-885.

13. Chen, Q., M.K. Ja, Y. Li, and K. Chua, Energy, economic and environmental (3E) analysis and multi-objective optimization of a spray-assisted low-temperature desalination system. Energy, 2018. 151: p. 387-401.

14. Wellmann, J., B. Meyer-Kahlen, and T. Morosuk, Exergoeconomic evaluation of a CSP plant in combination with a desalination unit. Renewable Energy, 2018. 128: p. 586-602.

15. Mutair, S. and Y. Ikegami, Experimental study on flash evaporation from superheated water jets: Influencing factors and formulation of correlation. International Journal of Heat and Mass Transfer, 2009. 52(23-24): p. 5643-5651.

16. Mutair, S. and Y. Ikegami, Experimental investigation on the characteristics of flash evaporation from superheated water jets for desalination. Desalination, 2010. 251(1-3): p. 103-111.

17. Ikegami, Y., H. Sasaki, T. Gouda, and H. Uehara, Experimental study on a spray flash desalination (influence of the direction of injection). Desalination, 2006. 194(1-3): p. 81-89.

18. El-Agouz, S., G.A. El-Aziz, and A. Awad, Solar desalination system using spray evaporation. Energy, 2014. 76: p. 276-283.

19. Chen, Q., M.K. Ja, Y. Li, and K. Chua, Evaluation of a solar-powered spray-assisted lowtemperature desalination technology. Applied energy, 2018. 211: p. 997-1008.

20. Maidment, G., I. Eames, M. Psaltas, A. Lalzad, and K. Yiakoumetti, Flash-type barometric desalination plant powered by waste heat from electricity power stations in Cyprus. Applied energy, 2007. 84(1): p. 66-77.

21. Chen, Q., Y. Li, and K. Chua, On the thermodynamic analysis of a novel low-grade heat driven desalination system. Energy conversion and management, 2016. 128: p. 145-159.

22. Chen, Q., M.K. Ja, Y. Li, and K. Chua, On the second law analysis of a multi-stage spray-assisted low-temperature desalination system. Energy conversion and management, 2017. 148: p. 13061316.

23. Wellmann, J., K. Neuhäuser, F. Behrendt, and M. Lehmann, Modeling an innovative lowtemperature desalination system with integrated cogeneration in a concentrating solar power plant. Desalination and Water Treatment, 2015. 55(12): p. 3163-3171.

24. Kim, Y.-D., K. Thu, H.K. Bhatia, C.S. Bhatia, and K.C. Ng, Thermal analysis and performance optimization of a solar hot water plant with economic evaluation. Solar Energy, 2012. 86(5): p. 1378-1395.

25. Kim, Y.-D., K. Thu, N. Ghaffour, and K.C. Ng, Performance investigation of a solar-assisted direct contact membrane distillation system. Journal of Membrane Science, 2013. 427: p. 345-364.

26. Sharqawy, M.H., J.H. Lienhard, and S.M. Zubair, Thermophysical properties of seawater: a review of existing correlations and data. Desalination and water treatment, 2010. 16(1-3): p. 354-380.

27. Wagner, W. and H.-J. Kretzschmar, IAPWS industrial formulation 1997 for the thermodynamic properties of water and steam. International Steam Tables: Properties of Water and Steam Based on the Industrial Formulation IAPWS-IF97, 2008: p. 7-150.

28. Chen, Q., K. Thu, T. Bui, Y. Li, K.C. Ng, and K. Chua, Development of a model for spray evaporation based on droplet analysis. Desalination, 2016. 399: p. 69-77.

29. Chen, Q., Y. Li, and K. Chua, Experimental and mathematical study of the spray flash evaporation phenomena. Applied Thermal Engineering, 2018. 130: p. 598-610.

30. Chen, Z., S. Furbo, B. Perers, J. Fan, and E. Andersen, Efficiencies of flat plate solar collectors at different flow rates. Energy Procedia, 2012. 30: p. 65-72.

31. Mahmoudi, H., N. Ghaffour, M.F. Goosen, and J. Bundschuh, Renewable Energy Technologies for Water Desalination. 2017: CRC Press. 
32. Coleman, H.W. and W.G. Steele, Experimentation, validation, and uncertainty analysis for engineers. 2018: John Wiley \& Sons. 